\title{
Physiological role of the respiratory quinol oxidase in the anaerobic nitrite-reducing methanotroph 'Candidatus Methylomirabilis oxyfera'
}

Correspondence

Ming L. Wu

m.wu@science.ru.nl

Received 3 September 2010 Revised 9 November 2010 Accepted 10 November 2010

\author{
Ming L. Wu, ${ }^{1}$ Simon de Vries, ${ }^{2}$ Theo A. van Alen, ${ }^{1}$ Margaret K. Butler, ${ }^{1} \dagger$ \\ Huub J. M. Op den Camp, ${ }^{1}$ Jan T. Keltjens, ${ }^{1}$ Mike S. M. Jetten ${ }^{1,2}$ \\ and Marc Strous $1,3,4$
}

${ }^{1}$ Department of Microbiology, Institute of Wetland and Water Research (IWWR), Radboud University
Nijmegen, Heyendaalsweg 135, 6525 AJ Nijmegen, The Netherlands
${ }^{2}$ Department of Biotechnology, Delft University of Technology, Julianalaan 67, 2628 BC Delft,
The Netherlands
${ }^{3}$ Max Planck Institute for Marine Microbiology, Celsiusstr. 1, D-28359 Bremen, Germany
${ }^{4}$ Centre for Biotechnology, University of Bielefeld, Postfach 100131, D-33501 Bielefeld, Germany

The anaerobic nitrite-reducing methanotroph 'Candidatus Methylomirabilis oxyfera' ('Ca. M. oxyfera') produces oxygen from nitrite by a novel pathway. The major part of the $\mathrm{O}_{2}$ is used for methane activation and oxidation, which proceeds by the route well known for aerobic methanotrophs. Residual oxygen may serve other purposes, such as respiration. We have found that the genome of ' $\mathrm{Ca}$. M. oxyfera' harbours four sets of genes encoding terminal respiratory oxidases: two cytochrome $c$ oxidases, a third putative bo-type ubiquinol oxidase, and a cyanideinsensitive alternative oxidase. Illumina sequencing of reverse-transcribed total community RNA and quantitative real-time RT-PCR showed that all four sets of genes were transcribed, albeit at low levels. Oxygen-uptake and inhibition experiments, UV-visible absorption spectral characteristics and EPR spectroscopy of solubilized membranes showed that only one of the four oxidases is functionally produced by ' $\mathrm{Ca}$. M. oxyfera', notably the membrane-bound bo-type terminal oxidase. These findings open a new role for terminal respiratory oxidases in anaerobic systems, and are an additional indication of the flexibility of terminal oxidases, of which the distribution among anaerobic micro-organisms may be largely underestimated.

\section{INTRODUCTION}

In 2006, a microbial enrichment culture was described that coupled anaerobic methane oxidation (AMO) to denitrification (Raghoebarsing et al., 2006). This culture was dominated (up to $80 \%$ ) by a bacterium, provisionally named 'Candidatus Methylomirabilis oxyfera' (' $\mathrm{Ca}$. M. oxyfera') (Ettwig et al., 2010), which formed a consortium with archaea. The archaea made up approximately $10 \%$ of the community. Continued anaerobic enrichment resulted in the disappearance of archaea after 2 years, indicating

tPresent address: Australian Institute for Bioengineering and Nanotechnology, University of Queensland, Brisbane 4072, Australia.

Abbreviations: $\mathrm{CcO}$, cytochrome $c$ oxidase; cyt $c$, cytochrome $\mathrm{c}$; $\mathrm{HCO}$, haem-copper oxidase; pMMO, particulate methane monooxygenase; qRT-PCR, quantitative RT-PCR; TMPD, $N, N, N^{\prime}, N^{\prime}$-tetramethyl-p-phenylenediamine; SHAM, salicylhydroxamic acid; UbqO, ubiquinol oxidase.

Two supplementary tables and three supplementary figures are available with the online version of this paper. that ' $C a$. M. oxyfera' could also perform the process in the absence of archaea (Ettwig et al., 2008). By metagenomic sequencing of the total microbial community, the complete genome of ' $C a$. M. oxyfera' was reconstructed (Ettwig et al., 2010). Genes encoding known enzymes involved in anaerobic alkane activation were absent. Instead, all genes encoding the enzymes of the aerobic methane oxidation pathway were found, including the particulate methane monooxygenase (pMMO). This enzyme performs the first step, the oxidation of methane to methanol, a reaction strictly dependent on molecular oxygen (Hakemian \& Rosenzweig, 2007). Next, all genes of the canonical denitrification pathway were present in the genome of ' $\mathrm{Ca}$. M. oxyfera', except those encoding nitrous oxide reductase. This enzyme complex catalyses the last step in the denitrification pathway, the reduction of nitrous oxide $\left(\mathrm{N}_{2} \mathrm{O}\right)$ to molecular nitrogen. Its absence was unexpected, since it was well established that ' $\mathrm{Ca}$. M. oxyfera' produces $\mathrm{N}_{2}$ as the end product of nitrite reduction during methane oxidation (equation 1) (Raghoebarsing et al., 2006): 
$3 \mathrm{CH}_{4}+8 \mathrm{NO}_{2}^{-}+8 \mathrm{H}^{+} \rightarrow 3 \mathrm{CO}_{2}+4 \mathrm{~N}_{2}+10 \mathrm{H}_{2} \mathrm{O}$

Subsequent experiments with ${ }^{15} \mathrm{~N}$ - and ${ }^{18} \mathrm{O}$-labelled substrates showed the intermediate formation of nitric oxide (NO), but not of $\mathrm{N}_{2} \mathrm{O}$. Quite surprisingly, molecular oxygen was also an intermediate (Ettwig et al., 2010). These findings suggested an alternative denitrification pathway. In this, $\mathrm{N}_{2}$ and $\mathrm{O}_{2}$ would be formed by the disproportionation of $\mathrm{NO}$ by the action of a dismutase-like enzyme, analogous to the chlorate dismutase described by van Ginkel et al. (1996).

Considering the $3: 8$ stoichiometry shown in equation (1), four molecules of $\mathrm{O}_{2}$ will be generated from eight molecules of nitrite, of which only three are required for methane activation by the methane monooxygenase. Thus, $25 \%$ of the oxygen produced needs to be consumed in another process, possibly respiration by a terminal oxidase. The present study addresses that possibility.

In bacteria, a multiplicity of terminal oxidases is found, most of which act as proton pumps. They differ in the electron donor used, notably cytochrome $c$ (cyt $c$ ) or quinol, $\mathrm{O}_{2}$ affinity, subunit composition, redox centre architecture and sensitivity to inhibitors. The majority of known bacterial terminal oxidases belong to the haemcopper superfamily (e.g. $a a_{3^{-}}, c a a_{3}, b a_{3^{-}}, c b b_{3^{-}}$and bo-type oxidases). Membership of the superfamily is based on the sequence similarity of the largest subunit (subunit I) and the presence of six positionally conserved axial ligands that coordinate the redox-active metal centre. The superfamily is divided into the quinol- (ubiquinol oxidase; UbqO) and cytochrome $c$-dependent (cytochrome $c$ oxidase; $\mathrm{CcO}$ ) oxidase families. The discriminating feature is the presence of an additional redox centre $\left(\mathrm{Cu}_{\mathrm{A}}\right)$ in the latter, located within the hydrophilic domain of subunit II, which serves as the electron acceptor from reduced cyt $c$. Although a $\mathrm{CcO}$, the $c b b_{3}$-type oxidase is an exception characterized by the absence of $\mathrm{Cu}_{\mathrm{A}}$; nevertheless, the function is suggested to be compensated by the $c$-type haems that are covalently bound to the smaller subunits (GarcíaHorsman et al., 1994; Pitcher \& Watmough, 2004). Outside the superfamily, two other terminal oxidases are known: the haem-only quinol-linked $b d$-type oxidase and the cyanide-insensitive alternative oxidase (AOX). bdType oxidases are present in numerous bacterial species and are associated with microaerobic respiration, due to their high affinity for $\mathrm{O}_{2}$ (Baughn \& Malamy, 2004; Das et al., 2005; Frazão et al., 2000). AOXs are quinol-dependent and belong to the membrane-bound diiron carboxylate proteins (Berthold \& Stenmark, 2003). Unlike the oxidases of the haem-copper superfamily, $b d$ - and AOX-type oxidases do not pump protons.

To explore the putative role of $\mathrm{O}_{2}$ in respiration by ' $\mathrm{Ca}$. M. oxyfera', we searched the genome for the presence of known terminal oxidases. Four sets of genes encoding different types of respiratory oxygen reductases were found. In addition, we investigated their transcription and expression by a complementary array of methods, including deep sequencing of extracted RNA, quantitative real-time RT-PCR (qRT-PCR) of reverse-transcribed extracted RNA, and UV-visible and EPR spectroscopy of membrane fractions prepared from ' $\mathrm{Ca}$. M. oxyfera' enrichment cultures, as well as oxygen respiration and inhibition studies. The results show that ' $\mathrm{Ca}$. M. oxyfera' transcribes and expresses at least one functional terminal oxidase, most likely a bo-type quinol-dependent oxidase.

\section{METHODS}

Growth of 'Ca. M. oxyfera'. 'Ca. M. oxyfera' (strain 'Twente') was enriched and cultured in an anoxic sequencing batch reactor (15 l) at $30{ }^{\circ} \mathrm{C}$ on a mineral medium containing $10 \mathrm{mM}$ nitrite and $3 \mathrm{mM}$ nitrate as described previously (Ettwig et al., 2010; Raghoebarsing et al., 2006). The medium was continuously sparged with a mixture of $\mathrm{Ar} / \mathrm{CO}_{2}(95: 5, \mathrm{v} / \mathrm{v})$ and the culture with $\mathrm{CH}_{4} / \mathrm{CO}_{2}(95: 5$, v/v, purity $>99.995 \%$, Air Liquide). Oxygen levels were always below the limit of detection as monitored by an $\mathrm{O}_{2}$ electrode. In the steady-state enrichment culture used in this work, the organism made up approximately $80 \%$ of the bacterial population. The remainder of the community $(20 \%)$ was highly diverse and evenly distributed (Ettwig et al., 2010). For the experiments, cells from the enrichment culture were harvested by centrifugation $\left(6000 \mathrm{~g}, 4{ }^{\circ} \mathrm{C}, 10 \mathrm{~min}\right)$ without any precautions to prevent exposure to oxygen.

Sequence analysis. Sequences of the different types of haem-copper oxidase (HCOs), $b d$-type oxidase and the main subunit of nitric oxide reductase (NorB) were extracted from GenBank. 'Ca. M. oxyfera' terminal oxidase sequences were retrieved from the genome available under GenBank accession number FP565575. Multiple sequence alignments were generated using the CLUSTAL w program (Thompson et al., 1994) and imported into MEGA 4 software (Tamura et al., 2007), followed by manual adjustments where necessary. Transmembrane protein topology was predicted using the TMHмM program (Krogh et al., 2001; Sonnhammer et al., 1998) (http://www.cbs.dtu.dk/ services/TMHMM-2.0/). The phylogenetic tree was constructed from a distance matrix using the neighbour-joining method (Saitou \& Nei, 1987), and confidence intervals were calculated using a bootstrap method (Felsenstein, 1985) with 1000 replications; both methods are included in the MEGA 4 software.

DNA and RNA isolation. Both DNA and RNA were isolated from $2 \mathrm{ml}$ reactor samples $(\sim 13.5 \mathrm{mg}$ wet weight). For DNA isolation, centrifuged biomass was resuspended in $2 \mathrm{ml} 120 \mathrm{mM}$ sodium phosphate buffer, $\mathrm{pH} 7.5$, in the presence of glass beads $(\sim 0.3 \mathrm{~g}$, $0.25 \mathrm{~mm}$ diameter). Cells were disrupted by bead-beating for $15 \mathrm{~s}$ and DNA was isolated according to Kowalchuk et al. (2004). RNA was isolated using the RiboPure-Bacteria kit (Ambion, AM1925). After RNA isolation, an additional DNase treatment was performed. Purity of the DNA and RNA preparations was assessed by $0.7 \%$ agarose gel electrophoresis, and concentrations were measured with a NanoDrop ND-1000 spectrophotometer (Isogen Life Science).

Illumina sequencing of total community RNA. Illumina sequencing had been performed previously (Ettwig et al., 2010), and the data are available under NCBI accession number GSE18535.

Quantitative real-time PCR (qRT-PCR). qRT-PCR primers were designed to target the genes for the subunits I of three HCOs (HCO 1, HCO 2 and HCO 3), the AOX gene and pmoA. Primer sequences, expected amplicon lengths, and annealing temperatures for the primers and sets are specified in Supplementary Table S1. For the generation of standard curves, PCR products obtained after PCR on 
DNA of ' $C a$. M. oxyfera' of each primer combination were cloned using the pGEM-T Easy cloning kit (Promega) and XL1 Blue Escherichia coli competent cells. Plasmids were isolated and purified with the Gene JET Plasmid Miniprep kit (Fermentas Life Sciences). First-strand cDNA was constructed with RevertAid Minus M-MuLV reverse transcriptase (Fermentas Life Sciences), according to the protocol provided, using gene-specific primers. First-strand cDNA was used as a template in qRT-PCR. Each cDNA sample was amplified in triplicate and the mean result was taken to give a single copy number. Amplification and detection were performed using a Bio-Rad iQ5 Cycler and Real-Time Detection system with an initial denaturation step at $95{ }^{\circ} \mathrm{C}$ for $10 \mathrm{~min}$, followed by 40 cycles at $95{ }^{\circ} \mathrm{C}$ for $15 \mathrm{~s}$, an annealing step at the temperatures indicated in Supplementary Table S1 for $1 \mathrm{~min}$, an elongation step at $72{ }^{\circ} \mathrm{C}$ for $1 \mathrm{~min}$, followed by a final elongation step at $72{ }^{\circ} \mathrm{C}$ for $5 \mathrm{~min}$. Transcript numbers were quantified using ABI Prism 7000 sequence detection software. Automatic analysis was selected for the baseline settings and the threshold cycle $\left(C_{\mathrm{t}}\right)$ relative fluorescence units (RFU) value was set at 200. Slope, $y$ axis intercept and the coefficient of determination $\left(r^{2}\right)$ were calculated for each standard curve. Amplification efficiency $(E)$ was calculated using the equation $E=\left(10^{1 / m}-1\right) \times 100$, where $m$ is the slope of the standard curve.

Preparation of cell-free extract, membrane isolation and solubilization. Approximately $1.3 \mathrm{~g}$ of cells (wet weight) was washed three times in $20 \mathrm{mM}$ Tris/ $\mathrm{HCl}, \mathrm{pH} 8.0$, and resuspended in $5 \mathrm{ml}$ buffer A, containing $50 \mathrm{mM}$ Tris/ $\mathrm{HCl}$, pH 8.0, 1 mM EDTA, $0.5 \mathrm{mM}$ PMSF and a few grains of solid DNase. Cells were broken by passing the cell suspension three times through a French pressure cell operating at $110 \mathrm{MPa}$. Cell debris was removed by centrifugation $(6000 \mathrm{~g}, 15 \mathrm{~min}$, $4{ }^{\circ} \mathrm{C}$ ) and the supernatant containing $2.47 \mathrm{mg}$ protein $\mathrm{ml}^{-1}$ was collected as a cell-free extract. The membrane fraction was recovered as the pellet after ultracentrifugation $\left(143000 \mathrm{~g}, 60 \mathrm{~min}, 4^{\circ} \mathrm{C}\right)$ of cell-free extract. The pellet was resuspended in $50 \mathrm{mM}$ Tris/ $\mathrm{HCl}$ buffer, $\mathrm{pH} 8.0$, washed twice and resuspended in $1.5 \mathrm{ml}$ of the same buffer. Membrane proteins were solubilized by adding CHAPS to a final concentration of $10 \mathrm{mM}$. After incubation with gentle stirring for $1 \mathrm{~h}$ at $4{ }^{\circ} \mathrm{C}$, the suspension was centrifuged $\left(6000 \mathrm{~g}, 15 \mathrm{~min}, 4{ }^{\circ} \mathrm{C}\right)$ and the resulting clear supernatant containing $0.47 \mathrm{mg}$ membrane proteins $\mathrm{ml}^{-1}$ was immediately used in the assays.

Protein determination. Protein content of the samples was determined by the method of Bradford (1976) using a Bio-Rad protein assay kit with BSA as standard.

Optical spectroscopy. UV-visible difference spectra of CHAPSsolubilized membranes were recorded in $1 \mathrm{~cm}$ path-length cuvettes at room temperature on a Varian Cary Eclipse spectrophotometer. Reduced-minus-oxidized difference spectra of the solubilized membrane fractions were recorded by measuring the dithionite-reduced spectrum of the sample against the air-oxidized one. To reduce the cytochromes in the preparation, a few grains of solid dithionite were added and the difference spectrum was recorded immediately. To obtain a CO-reduced-minus-reduced difference spectrum, CO was bubbled through the measuring cuvette for $10 \mathrm{~min}$ before the recordings were made.

EPR spectroscopy. X-band EPR spectroscopy was performed on a Bruker ER200D spectrometer (von Wachenfeldt et al., 1994). The spectrometer was equipped with a home-built He-flow system. Spectra of the oxidized and dithionite-reduced membrane fractions were recorded at 18 and $12 \mathrm{~K}$, respectively. Other settings for both spectra were: frequency, $9.39 \mathrm{GHz}$; modulation amplitude, $1 \mathrm{mT}$; microwave power, $2 \mathrm{~mW}$.

Oxygen reduction measurements. Oxygen consumption by ' $\mathrm{Ca}$. M. oxyfera' cell-free extracts prepared in buffer A (1.37 mg protein $\mathrm{ml}^{-1}$ ) was measured polarographically at $30{ }^{\circ} \mathrm{C}$ employing a microsensor Clarke-type electrode (Unisense). When using different enzyme concentrations, oxidase activities were proportional to the amount of protein applied in the assays. Anoxic stock solutions of the substrates and inhibitors were prepared in $100 \% \mathrm{He}$ gas prior to injection into the reaction mixtures. Bovine heart cyt $c(25 \mu \mathrm{M})$ and $N, N, N^{\prime}, N^{\prime}$-tetramethyl-p-phenylenediamine (TMPD) (0.4 mM) oxidase activities were assayed in the presence of $2 \mathrm{mM}$ sodium ascorbate. Ubiquinone-1 $\left(\mathrm{Q}_{1}\right)(40 \mu \mathrm{M})$ together with $10 \mathrm{mM}$ DTT was used to assay $\mathrm{UbqO}$ activity. In the inhibition assays, samples were pre-incubated with either salicylhydroxamic acid (SHAM) or cyanide $\left(\mathrm{CN}^{-}\right)$for $5 \mathrm{~min}$; prolonged pre-incubation (up to $30 \mathrm{~min}$ ) had no further effect. The donor-specific oxygen consumption rates were corrected for the auto-oxidation and endogenous respiration rates.

\section{RESULTS}

\section{Identification of oxidase-type ORFs in the 'Ca. M. oxyfera' genome}

BLAST analysis of the genome of ' $C a$. M. oxyfera' revealed the presence of four gene clusters encoding sequences similar to known terminal oxidases (Fig. 1). The same four gene clusters were retrieved in BLAST searches with the total community DNA obtained by 454 pyrosequencing data as the template. Three of these were members of the $\mathrm{HCO}$ superfamily, hereafter referred as to HCO $1, \mathrm{HCO} 2$ and HCO 3, and the fourth was related to the diiron carboxylate AOX. The HCO 1 cluster comprised four genes. Between the genes encoding subunit III and subunit IV, an additional ORF was found by automatic annotation, which would be transcribed from the opposite strand, partly overlapping with subunit IV and potentially encoding a polypeptide with a weak homology to a hypothetical protein from the plant Vitis vinifera (NCBI accession no. CAN_68923). However, closer inspection shows the lack of a ribosome-binding site, suggesting this ORF to be a pseudogene. The HCO 2 and HCO 3 clusters both contained two genes, representing subunits I and II of the known enzyme complexes. The gene organization of the three HCOs was as commonly found in other bacteria: subunit II preceded subunit I, followed by the remaining subunits, if present (García-Horsman et al., 1994). The AOX homologue was encoded by a single gene.

\section{Characteristics of HCO 1, HCO 2, HCO 3 and AOX}

Table 1 summarizes the general characteristics of the four terminal oxidase clusters. The phylogenetic tree of the subunits I of HCO 1, HCO 2, HCO 3 and corresponding homologous genes from other organisms shows that HCO 1 and HCO 3 branch with $a a_{3}$-type and $b a_{3}$-type cyt $c$ oxidases, respectively (Supplementary Fig. S1). HCO 2 appeared to be more distant from all the sequences analysed. Alignment of the subunit I amino acid sequences of the three HCOs with those of other HCOs revealed the conserved six canonical histidines required as ligands for both the bimetallic centre and $\mathrm{Cu}_{\mathrm{B}}$ (Supplementary Fig. S2) 


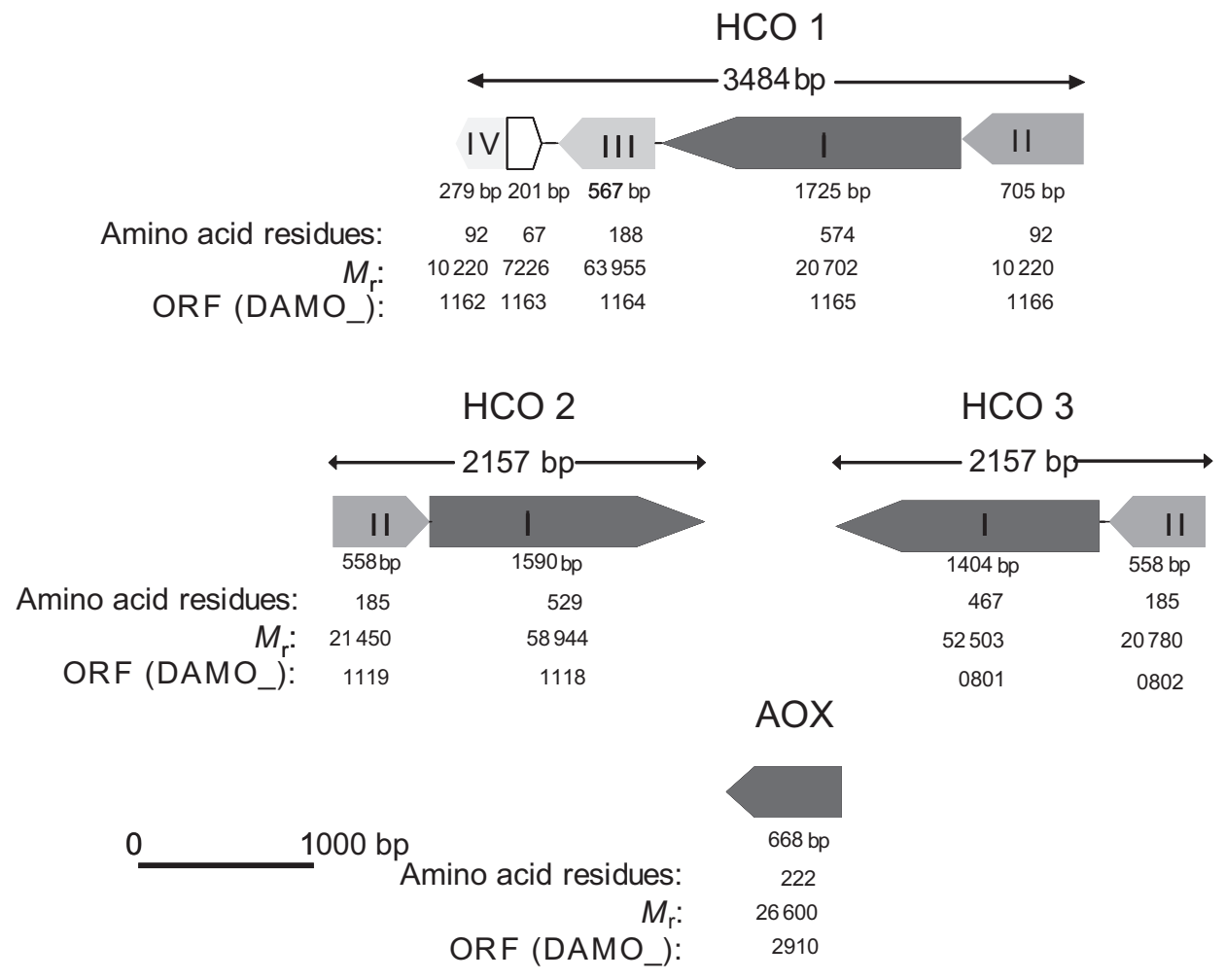

Fig. 1. Physical map of the gene clusters found in the genome that putatively encode HCOs and the AOX. Roman numerals within the arrows indicate the subunit encoded by the gene. The unfilled arrow in the HCO 1 cluster represents a pseudogene.

(García-Horsman et al., 1994; Musser et al., 1993). Hydropathy plots of subunit I and subunit II indicated the expected 12 and two membrane-spanning regions, respectively, for all three HCOs, their locations being very similar to those of the $a a_{3}$-type oxidases from bovine heart and $P$. denitrificans.

Table 1. Summary of the characteristics of the four terminal oxidases from ' $\mathrm{Ca}$. M. oxyfera'

\begin{tabular}{|c|c|c|c|c|}
\hline Complex & Identity (\%) & ORF identifier & Type & Evidence \\
\hline Subunit I & $38.5^{\star}$ & DAMO_1165 & $a a_{3}$ & Global sequence homology and conserved residues \\
\hline Subunit III & $24.7^{\star}$ & DAMO_1164 & & \\
\hline Subunit IV & $7.2^{*}$ & DAMO_1162 & & \\
\hline \multicolumn{5}{|l|}{ HCO 2} \\
\hline $\begin{array}{l}\text { Subunit II } \\
\text { HCO } 3\end{array}$ & $13.7 \dagger$ & DAMO_1119 & & \\
\hline Subunit I & $24.2 \ddagger$ & DAMO_0801 & $b a_{3}$ & Global sequence homology and conserved residues \\
\hline Subunit II & $19.0 \ddagger$ & DAMO_0802 & & \\
\hline AOX & $22.2 \$$ & DAMO_2910 & & Global sequence homology and conserved residues \\
\hline
\end{tabular}

*Amino acid percentage identity compared with the P. denitrificans aa 3 -type CcO (NCBI accession no. YP_916807; YP_918081; YP_918077; YP_914242).

$\dagger$ Amino acid percentage identity compared with the E. coli bo-type UbqO (GenBank accession no. ACI70268; ACI70263).

$\ddagger$ Amino acid percentage identity compared with the Thermus thermophilus ba $a_{3}$-type CcO (GenBank accession no. AAB00370; AAB00369).

§Amino acid percentage identity compared with the N. azolla AOX (NCBI accession no. ZP_03766891). 
Subunit II of all CcOs, except for the $c b b_{3}$-type, is characterized by the presence of conserved ligands within the $\mathrm{Cu}_{\mathrm{A}}$ binding site (His-210, Cys-245, Cys-249, His-253, Met-256 and Glu-250 in the $P$. denitrificans numbering scheme) (Abramson et al., 2001; García-Horsman et al., 1994; Musser et al., 1993; Pitcher \& Watmough, 2004; Speno et al., 1995). All these proposed ligands were found to be conserved in both HCO 1 and HCO 3, supporting their role as CcOs (Supplementary Fig. S2). In HCO 2, however, only Met-256 and Glu-250 were conserved. Instead of copper, the $c b b_{3}$-type $\mathrm{CcO}$ small subunit binds a haem $c$, which is signified by a conserved (CXXCH-//-MP) motif. Again, the motif was not found in $\mathrm{HCO} 2$. The absence of both $\mathrm{Cu}_{\mathrm{A}}$ and haem $c$ binding motifs would leave HCO 2 a role as a UbqO, notably of the $b o$-type. In agreement with this, we were able to find in the genome and detect in the transcriptome the gene encoding the key enzyme for haem $\mathrm{O}$ synthesis, protohaem IX farnesyltransferase (Supplementary Table S2) (ORF identifier DAMO_1659) (Saiki et al., 1993). An ORF encoding a putative haem A synthase was also found in the genome (ORF identifier DAMO_1660).

The translated sequence of the AOX gene in the genome of ' $C a$. M. oxyfera' was most similar to the AOX from Nostoc azolla (NCBI accession no. ZP_03766891; 22.2 \% identity). Hydropathy plots predicted a single membrane-spanning region. All iron ligands in the four-helix bundle were found to be conserved (Supplementary Fig. S3).

\section{Transcription}

To investigate whether the terminal oxidase genes were transcribed, we applied two complementary methods, deep sequencing of RNA and qRT-PCR, using the pMMO large subunit $(p m o A)$ as a reference (Table 2 and Supplementary Table S2). For the deep sequencing we took advantage of the massive parallel Illumina sequencing data of the total community RNA previously reported (Ettwig et al., 2010).

Illumina sequencing confirmed the transcription of the terminal oxidase genes, albeit at relatively low levels, especially if compared with the $P m o A$ gene (mean coverage of 44.9), which is one of the most abundantly expressed genes in ' $\mathrm{Ca}$.
M. oxyfera'. The mean coverage for DAMO_1162 and the DAMO_1163 pseudogene (mean coverage 3.7) obtained with Illumina sequencing (Supplementary Table S2) was substantially higher than that of other genes encoding terminal oxidases. However, most of the Illumina reads in this region mapped to two specific short DNA stretches within the DAMO_1163 pseudogene, including the overlapping part with DAMO_1162. This suggests that the transcripts were derived from small RNAs, rather than from mRNA. One may note that the expression levels of the terminal oxidases in the transcriptome were in the same range as approximately 1600 other gene transcripts (from a total of 5025 gene transcripts), comprising genes and their intergenic regions encoding a variety of essential metabolic functions.

qRT-PCR targeted subunit I of the three HCOs, AOX and pmoA; primers and probe sets are specified in Supplementary Table S1. For all primer sets analysed, transcripts were found. Copy numbers for $\mathrm{HCO} 1, \mathrm{HCO} 3$ and $\mathrm{AOX}$ were within the same order of magnitude, but the HCO 2 copy number was significantly lower. Even so, the copy number exceeded that of the corresponding negative control (which was notably lower than that of the others) by more than 1000 -fold, showing that the HCO 2 gene is indeed transcribed. Thus, both the Illumina transcriptome and qRT-PCR results show the transcription of all four putative terminal oxidases, albeit at low levels, especially if compared with $p m o A$.

\section{Spectroscopy}

Terminal oxidases are characterized by their optical absorption spectra, reduced-minus-oxidized and CO-difference spectra, and by the EPR properties of their redox-sensitive prosthetic groups. The UV-visible light spectra of ' $\mathrm{Ca}$. M. oxyfera' solubilized membranes showed Soret peaks at 413.5 and $432 \mathrm{~nm}$, and bands at 535, 552 and $563 \mathrm{~nm}$ peaks in the $\alpha / \beta$ region (Fig. 2). Overall, the spectra showed all features of the bo-type oxidase purified from E. coli (Kitada \& Krulwich, 1984; Puustinen \& Wikstrom, 1991). The Soret peaks at $413.5 / 432 \mathrm{~nm}$ in the CO-difference spectrum were very close to those of the E. coli enzyme $(416 / 430 \mathrm{~nm})$. Also, the positive peaks at $563 / 535 \mathrm{~nm}$ were similar to the E. coli

Table 2. qRT-PCR characteristics and copy numbers of the subunits I of the three $\mathrm{HCOs}(\mathrm{HCO} 1, \mathrm{HCO} 2$ and $\mathrm{HCO} 3$ ), the AOX and the $\mathrm{pMMO}(p m \circ A)$

The negative controls were performed without cDNA. $r^{2}$, Coefficient of determination.

\begin{tabular}{|lcccccc|}
\hline Gene & Slope & Efficiency (\%) & $y$ Intercept & $\boldsymbol{r}^{2}$ & Negative control & Copy number $^{*}$ \\
\hline HCO 1 & 3.29 & 99.2 & 40.91 & 0.998 & $2.62 \times 10^{2}$ & $8.64 \times 10^{5}$ \\
HCO 2 & 3.20 & 96.5 & 39.17 & 0.999 & $2.02 \times 10^{0}$ & $3.03 \times 10^{3}$ \\
HCO 3 & 3.44 & 103.9 & 41.99 & 0.999 & $5.75 \times 10^{1}$ & $1.44 \times 10^{6}$ \\
AOX & 3.26 & 98.4 & 41.24 & 0.996 & $1.08 \times 10^{1}$ & $2.25 \times 10^{5}$ \\
PmoA & 3.33 & 100.3 & 39.65 & 0.997 & $1.51 \times 10^{3}$ & $6.85 \times 10^{7}$ \\
\hline
\end{tabular}

${ }^{\star}$ Copy number per nanogram of total RNA. 


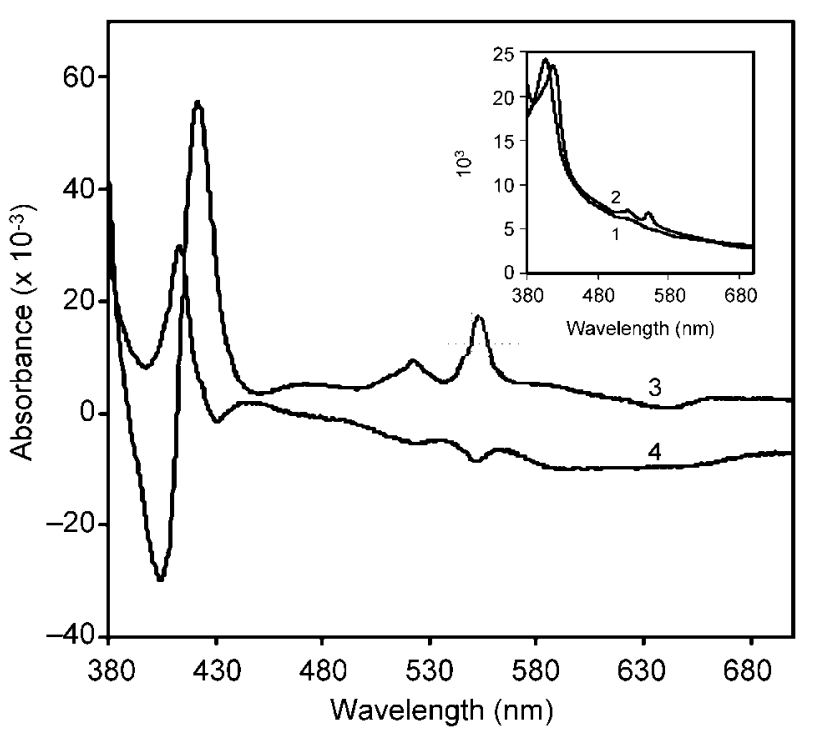

Fig. 2. UV-visible absorption spectra of 'Ca. M. oxyfera' CHAPSsolubilized membranes. (1) Air-oxidized, (2) dithionite-reduced, (3) reduced-minus-oxidized and (4) CO-reduced-minus-reduced difference spectra. The protein concentration was $0.47 \mathrm{mg} \mathrm{ml}^{-1}$.

oxidase $(568 / 535 \mathrm{~nm})$, although the negative peak at $552 \mathrm{~nm}$ differed from the $559-560 \mathrm{~nm}$ peak in E. coli. The reducedminus-oxidized spectra were dominated by various types of $c$-type cytochromes, which likely include the major enzyme in nitrite reduction, $c d 1$ nitrite reductase $(c d 1 \mathrm{Nir})$ (absorbance around 630-650 nm). However, the absorption characteristics of NO reductase (absorbance around $599 \mathrm{~nm}$ ) (Suharti et al., 2001) could not be discerned. This is remarkable, since the ' $\mathrm{Ca}$. M. oxyfera' genome encodes three homologues of the enzyme (Supplementary Fig. S1), two of these being highly expressed in the transcriptome and in the proteome (Ettwig et al., 2010).

The X-band EPR spectrum of oxidized and reduced ' $C a$. M. oxyfera' membrane preparations is presented in Fig. 3 . Oxidized membranes showed a large signal with EPR parameters $\left(\mathrm{g}_{/ /}=2.217 ; \mathrm{A}_{/ /}=196\right.$ Gauss; $\left.\mathrm{g}_{\perp}=2.053\right)$ that are typical for a type- $2 \mathrm{Cu}$ centre. A commonly found freeradical signal at $\mathrm{g}=2$ could not be assigned specifically. Reduced membranes displayed a broad signal around $\mathrm{g}=2.04$, presumably derived from multiple $\mathrm{Fe}-\mathrm{S}$ centres in mutual magnetic interaction, such as in nitrate reductase. Now, the type- $2 \mathrm{Cu}$ spectrum was not detectable, as expected after the reduction of $\mathrm{Cu}^{2+}$ to $\mathrm{Cu}^{1+}$. The large type- $2 \mathrm{Cu}$ signal most likely derived from pMMO (Lemos et al., 2000). Its intensity may have masked, if present at all, a $\mathrm{CcO} \mathrm{Cu}_{\mathrm{A}}$ paramagnetic signal near $\mathrm{g}=2$ (Lauraeus et al., 1991; von Wachenfeldt et al., 1994). Furthermore, an EPR paramagnetic signal of the anti-ferromagnetically coupled $\mathrm{Fe}(\mathrm{II}) / \mathrm{Fe}(\mathrm{III})$ state of the diiron centre of AOX was not observed in the membrane preparations. Again, if present, this particular signal could have gone undetected, since it is only seen in highly purified (Berthold et al., 2002; Moore

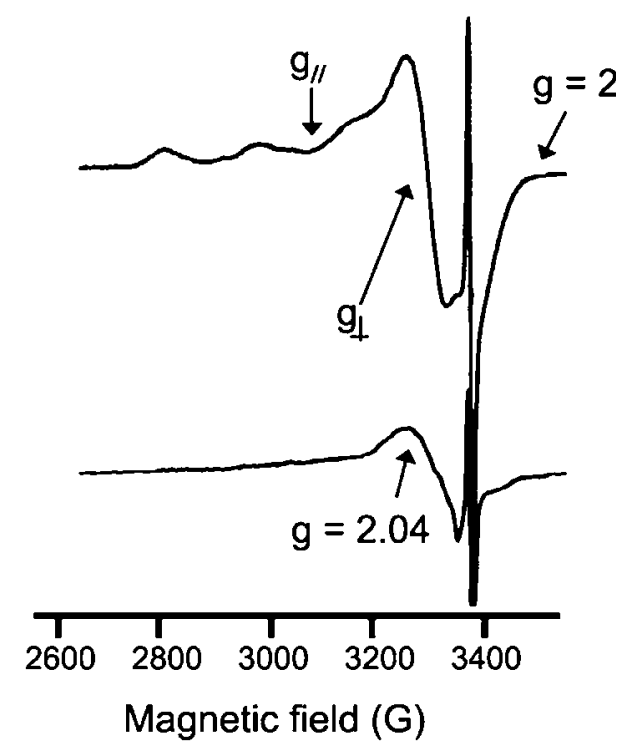

Fig. 3. X-band EPR spectra of air-oxidized (upper line) and dithionite-reduced membranes (lower line) of 'Ca. M. oxyfera'. The protein concentration was $2.04 \mathrm{mg} \mathrm{ml}^{-1}$, the temperature $12 \mathrm{~K}$. Instrument parameters are as described in Methods.

et al., 2008) and not in partially purified preparations (Berthold \& Siedow, 1993; Rich, 1978).

\section{Oxygen respiration and electron donor specificity}

Terminal oxidases are distinguished by the nature of the electron donor (reduced cyt $c$, quinols). To test the substrate use, ' $\mathrm{Ca}$. M. oxyfera' cell-free extracts were assayed for oxygen respiration rates with both types of reductant, and in the presence and absence of specific inhibitors (Table 3). The $\mathrm{O}_{2}$ consumption rate with

Table 3. Oxygen reduction activity and inhibition of ' $\mathrm{Ca}$. M. oxyfera' cell-free extracts

\begin{tabular}{|lc|}
\hline Substrate & $\begin{array}{c}\mathbf{O}_{\mathbf{2}} \text { consumption activity }^{\star}[\mathbf{n m o l} \\
\left.\mathbf{m i n}^{-\mathbf{1}}\left(\mathbf{m g ~ p r o t e i n}^{-1}\right)\right]\end{array}$ \\
\hline Endogenous & $3.1 \pm 3.1$ \\
cyt $c$ & $2.5 \pm 2.6$ \\
TMPD & 19.2 \\
cyt $c$ & $19.8 \pm 2.7$ \\
$\quad+1 \mathrm{mM} \mathrm{CN}^{-}$ & $20.2 \pm 2.4$ \\
$+5 \mathrm{mM} \mathrm{CN}^{-}$ & $23.8 \pm 1.9$ \\
$\mathrm{Q}_{1} \mathrm{H}_{2}$ & $33.8 \pm 3.6$ \\
$+1 \mathrm{mM} \mathrm{CN}^{-}$ & $20.8 \pm 4.0$ \\
$+5 \mathrm{mM} \mathrm{CN}^{-}$ & $14.4 \pm 1.6$ \\
$+5 \mathrm{mM} \mathrm{SHAM}^{-}$ & $31.2 \pm 6.0$ \\
\hline
\end{tabular}

${ }^{*}$ Results are the means \pm SDs of at least three independent assays. Cellfree extract protein concentrations in the $(0.5 \mathrm{ml})$ polarographic chamber during the assay ranged between 0.78 and $2.74 \mathrm{mg} \mathrm{ml}^{-1}$. 
reduced cyt $c\left[2.5 \pm 2.6 \mathrm{nmol} \mathrm{m^{-1 }}(\mathrm{mg} \text { protein })^{-1}\right]$ equalled the endogenous one $\left[3.1 \pm 3.1 \mathrm{nmol} \mathrm{min}{ }^{-1}(\mathrm{mg}\right.$ protein $\left.)^{-1}\right]$. The TMPD respiration rate $\left[19.2 \mathrm{nmol} \mathrm{min}{ }^{-1}\right.$ (mg protein $\left.)^{-1}\right]$ was not stimulated by the addition of cyt $c$ $\left[19.8 \mathrm{nmol} \mathrm{min}{ }^{-1}(\mathrm{mg} \text { protein })^{-1}\right]$. Neither was the oxygen consumption rate with the TMPD/cyt $c$ pair inhibited by 1 or $5 \mathrm{mM} \mathrm{CN}^{-}$, as expected for a CcO-type terminal oxidase. The experiments show the apparent absence of a cyt $c$-dependent activity. When assayed with reduced ubiquinone, the $\mathrm{O}_{2}$ consumption rate was $33.8 \pm 3.6 \mathrm{nmol}$ $\min ^{-1}$ (mg protein $)^{-1}$. Now, the activity was inhibited by approximately 40 and $60 \%$ by 1 and $5 \mathrm{mM} \mathrm{CN}^{-}$, respectively. In contrast, SHAM, a potent specific inhibitor of AOX (Schonbaum et al., 1971), did not affect the ubiquinol-dependent respiration rate.

\section{DISCUSSION}

Two properties of ' $\mathrm{Ca}$. M. oxyfera' are unique in comparison with all other bacteria: the coupling of anaerobic methane oxidation to denitrification and the ability to produce oxygen intracellularly from nitric oxide for methane oxidation (Ettwig et al., 2010; Raghoebarsing et al., 2006; Wu et al., 2011). Enrichment cultures used here and in other studies coupled methane oxidation to nitrite reduction in a near 3:8 stoichiometry, as expected from equation (1), indicating that all oxygen formed is exclusively used by the methanotroph, rather than by members of the highly diverse remainder of the population. The major part $(75 \%)$ of the oxygen is employed for the activation/oxidation of methane by methane monooxygenase, leaving the residual $25 \%$ for other purposes. In fact, the genome of ' $\mathrm{Ca}$. M. oxyfera' contains four different sets of genes encoding terminal oxidases.

Experiments described in this paper demonstrate that cell extracts prepared from the 'Ca. M. oxyfera' culture are capable of oxygen respiration. In fact, the genome of ' $\mathrm{Ca}$. M. oxyfera' contains four different sets of genes encoding terminal oxidases. Three of these (HCO 1-3) are members of the HCO superfamily (García-Horsman et al., 1994; Musser et al., 1993) and the fourth is a non-protonpumping AOX (Berthold \& Stenmark, 2003) (Fig. 1, Table 1 and Supplementary Figs S1-S3). A more detailed analysis suggested HCO 1 and HCO 3 to be $a a_{3}$-type and $b a_{3}$-type cyt $c$ oxidases, respectively, and HCO 2 to be a UbqO.

Illumina sequencing of the total community RNA and qRT-PCR of the HCO large subunits and of AOX showed that all four oxidases were transcribed, albeit at low levels as compared with the major catabolic gene $p m o A$, but nevertheless above the background level (Table 2 and Supplementary Table S2). Despite their transcription, neither the $\mathrm{HCO} 1$ nor the $\mathrm{HCO} 3 \mathrm{CcO}$, nor AOX seemed to be expressed functionally in detectable amounts. This was concluded from the lack of cyt $c$-dependent oxidase activity, and the lack of cyanide and SHAM inhibition (Table 3). Furthermore, the UV-visible (difference) spectra and the EPR spectra of membrane preparations did not reveal any features specific to the three oxidases, although putative signals may have been obscured by other more prominent patterns (Figs 2 and 3). In contrast, cell-free extracts exhibited a cyanide-sensitive quinol oxidase activity, whereas the CO-difference spectrum of membrane preparations was highly similar to that of bo-type UbqO purified from E. coli (Kitada \& Krulwich, 1984; Puustinen \& Wikstrom, 1991). Taken together, our findings argue for functional expression of a bo-type UbqO by ' $\mathrm{Ca}$. M. oxyfera', namely $\mathrm{HCO} 2$. Considering that the bo-type UbqO is a highly active enzyme, the enzyme purified from E. coli, for example, displays a specific activity of $>300 \mu \mathrm{mol} \mathrm{min}{ }^{-1}$ (mg protein) ${ }^{-1}$ (Kita et al., 1984), the low quinol oxidase activity found here $\left[33.8 \mathrm{nmol} \mathrm{m^{-1 }}(\mathrm{mg} \text { protein })^{-1}\right]$ is consistent with the low HCO 2 expression. Nevertheless, even this low activity complies with a role in oxygen respiration, taking into account that ' $\mathrm{Ca}$. M. oxyfera' is an extremely slow-growing and metabolically inert microorganism, oxidizing methane at a rate of only $1.7 \mathrm{nmol}$ $\min ^{-1}$ (mg protein) ${ }^{-1}$ (Ettwig et al., 2008).

One may note that the quinol-dependent oxygen consumption was only partly inhibited by cyanide (Table 3 ). This might indicate the presence of a cyanide-insensitive terminal oxidase in the preparation, such as the $b d$-type oxidase (Voggu et al., 2006). However, neither a search of the ' $\mathrm{Ca}$. M. oxyfera' genome nor the detailed analysis of the total community DNA 454 pyrosequencing data retrieved any sequences corresponding to a $b d$-type oxidase. Hence, the cause of the cyanide-insensitive UbqO activity remains unclear to us. It is conceivable that HCO 2 itself is relatively insensitive towards the inhibitor, which would not be surprising considering its phylogenetic divergence.

In conclusion, ' $\mathrm{Ca}$. M. oxyfera' produces oxygen as an intermediate of its catabolism. Part of the oxygen can be respired using reducing equivalents from the methane oxidation pathway. Experiments described in this paper strongly suggest the functional expression of a bo-type quinol-dependent terminal oxidase, notably HCO 2. Being a proton pump, the enzyme would permit the organism to conserve additional energy by oxygen respiration, next to denitrification. The other oxidases found in the ' $\mathrm{Ca}$. M. oxyfera' genome do not seem to be expressed at detectable levels, at least not under the conditions at which the organism was cultured in this study. Still, the presence in the genome of an apparently anaerobic micro-organism of no fewer than four terminal oxidases is conspicuous and highlights the need for more research on the role of terminal oxidases in anaerobes. The expression of bd-type oxidases in the acetogenic bacterium Morella (Das et al., 2005) and the pathogenic bacterium Bacteroides fragilis (Baughn \& Malamy, 2004), and the rubredoxin:oxygen oxidoreductase in Desulfovibrio (Frazão et al., 2000), are additional examples from other anaerobic micro-organisms. Finally, the present work suggests that the role of oxygen in systems considered to be anaerobic may be much more complex than previously thought. 


\section{ACKNOWLEDGEMENTS}

We thank Boran Kartal, Arjan Pol, Katharina F. Ettwig, Francisca Luesken and Wouter Maalcke (Department of Microbiology), and Bas E. Dutilh (Centre for Molecular and Biomolecular Informatics, Nijmegen Centre for Molecular Life, Radboud University, Nijmegen, the Netherlands) for discussions. This work was supported by the Dutch Science Foundation (NWO) Horizon Project 050-71-058.

\section{REFERENCES}

Abramson, J., Svensson-Ek, M., Byrne, B. \& Iwata, S. (2001). Structure of cytochrome $c$ oxidase: a comparison of the bacterial and mitochondrial enzymes. Biochim Biophys Acta 1544, 1-9.

Baughn, A. D. \& Malamy, M. H. (2004). The strict anaerobe Bacteroides fragilis grows in and benefits from nanomolar concentrations of oxygen. Nature 427, 441-444.

Berthold, D. A. \& Siedow, J. N. (1993). Partial purification of the cyanide-resistant alternative oxidase of skunk cabbage (Symplocarpus foetidus) mitochondria. Plant Physiol 101, 113-119.

Berthold, D. A. \& Stenmark, P. (2003). Membrane-bound diiron carboxylate proteins. Annu Rev Plant Biol 54, 497-517.

Berthold, D. A., Voevodskaya, N., Stenmark, P., Graslund, A. \& Nordlund, P. (2002). EPR studies of the mitochondrial alternative oxidase. J Biol Chem 277, 43608-43614.

Bradford, M. M. (1976). Rapid and sensitive method for the quantitation of microgram quantities of protein utilizing the principle of protein-dye binding. Anal Biochem 72, 248-254.

Das, A., Silaghi-Dumitrescu, R., Ljungdahl, L. G. \& Kurtz, D. M. (2005). Cytochrome $b d$ oxidase, oxidative stress, and dioxygen tolerance of the strictly anaerobic bacterium Moorella thermoacetica. J Bacteriol 187, 2020-2029.

Ettwig, K. F., Shima, S., van de Pas-Schoonen, K. T., Kahnt, J., Medema, M. H., op den Camp, H. J. M., Jetten, M. S. M. \& Strous, M. (2008). Denitrifying bacteria anaerobically oxidize methane in the absence of Archaea. Environ Microbiol 10, 3164-3173.

Ettwig, K. F., Butler, M. K., Le Paslier, D., Pelletier, E., Mangenot, S., Kuypers, M. M. M., Schreiber, F., Dutilh, B. E., Zedelius, J. \& other authors (2010). Nitrite-driven anaerobic methane oxidation by oxygenic bacteria. Nature 464, 543-548.

Felsenstein, J. (1985). Confidence limits on phylogenies: an approach using the bootstrap. Evolution 39, 783-791.

Frazão, C., Silva, G., Gomes, C. M., Matias, P., Coelho, R., Sieker, L., Macedo, S., Liu, M. Y., Oliveira, S. \& other authors (2000). Structure of a dioxygen reduction enzyme from Desulfovibrio gigas. Nat Struct Biol 7, 1041-1045.

García-Horsman, J. A., Barquera, B., Rumbley, J., Ma, J. X. \& Gennis, R. B. (1994). The superfamily of heme-copper respiratory oxidases. J Bacteriol 176, 5587-5600.

Hakemian, A. S. \& Rosenzweig, A. C. (2007). The biochemistry of methane oxidation. Annu Rev Biochem 76, 223-241.

Kita, K., Konishi, K. \& Anraku, Y. (1984). Terminal oxidases of Escherichia coli aerobic respiratory chain. I. Purification and properties of cytochrome $b_{562}-o$ complex from cells in the early exponential phase of aerobic growth. J Biol Chem 259, 3368-3374.

Kitada, M. \& Krulwich, T. A. (1984). Purification and characterization of the cytochrome oxidase from alkalophilic Bacillus firmus RAB. J Bacteriol 158, 963-966.

Kowalchuk, G. A., de Bruijn, F. J., Head, I. M., Akkermans, A. D. \& van Elsas, J. D. (2004). Molecular Microbial Ecology Manual (MMEM), 2nd edn, vol. 1. London: Kluwer Academic Publishing.
Krogh, A., Larsson, B., von Heijne, G. \& Sonnhammer, E. L. L. (2001). Predicting transmembrane protein topology with a hidden Markov model: application to complete genomes. J Mol Biol 305, 567-580.

Lauraeus, M., Haltia, T., Saraste, M. \& Wikstrom, M. (1991). Bacillus subtilis expresses two kinds of haem-A-containing terminal oxidases. Eur J Biochem 197, 699-705.

Lemos, S. S., Collins, M. L. P., Eaton, S. S., Eaton, G. R. \& Antholine, W. E. (2000). Comparison of EPR-visible $\mathrm{Cu}^{2+}$ sites in pMMO from Methylococcus capsulatus (Bath) and Methylomicrobium album BG8. Biophys J 79, 1085-1094.

Moore, A. L., Carré, J. E., Affourtit, C., Albury, M. S., Crichton, P. G., Kita, K. \& Heathcote, P. (2008). Compelling EPR evidence that the alternative oxidase is a diiron carboxylate protein. Biochim Biophys Acta 1777, 327-330.

Musser, S. M., Stowell, M. H. B. \& Chan, S. I. (1993). Comparison of ubiquinol and cytochrome- $c$ terminal oxidases - an alternative view. FEBS Lett 327, 131-136.

Pitcher, R. S. \& Watmough, N. J. (2004). The bacterial cytochrome $\mathrm{cbb}_{3}$ oxidases. Biochim Biophys Acta 1655, 388-399.

Puustinen, A. \& Wikstrom, M. (1991). The heme groups of cytochrome o from Escherichia coli. Proc Natl Acad Sci U S A 88, 6122-6126.

Raghoebarsing, A. A., Pol, A., van de Pas-Schoonen, K. T., Smolders, A. J. P., Ettwig, K. F., Rijpstra, W. I. C., Schouten, S., Damste, J. S. S., Op den Camp, H. J. M. \& other authors (2006). A microbial consortium couples anaerobic methane oxidation to denitrification. Nature 440, 918-921.

Rich, P. R. (1978). Quinol oxidation in Arum maculatum mitochondria and its application to the assay, solubilisation and partial purification of the alternative oxidase. FEBS Lett 96, 252-256.

Saiki, K., Mogi, T., Ogura, K. \& Anraku, Y. (1993). In vitro heme O synthesis by the cyoE gene product from Escherichia coli. J Biol Chem 268, 26041-26044.

Saitou, N. \& Nei, M. (1987). The neighbor-joining method: a new method for reconstructing phylogenetic trees. Mol Biol Evol 4, 406-425.

Schonbaum, G. R., Bonner, W. D., Jr, Storey, B. T. \& Bahr, J. T. (1971). Specific inhibition of the cyanide-insensitive respiratory pathway in plant mitochondria by hydroxamic acids. Plant Physiol 47, 124-128.

Sonnhammer, E. L., von Heijne, G. \& Krogh, A. (1998). A hidden Markov model for predicting transmembrane helices in protein sequences. Proc Int Conf Intell Syst Mol Biol 6, 175-182.

Speno, H., Taheri, M. R., Sieburth, D. \& Martin, C. T. (1995). Identification of essential amino acids within the proposed $\mathrm{Cu}_{\mathrm{A}}$ binding site in subunit II of cytochrome $c$ oxidase. J Biol Chem 270, 25363-25369.

Suharti, Strampraad, M. J. F., Schroder, I. \& de Vries, S. (2001). A novel copper A containing menaquinol NO reductase from Bacillus azotoformans. Biochemistry 40, 2632-2639.

Tamura, K., Dudley, J., Nei, M. \& Kumar, S. (2007). MEGA 4: molecular evolutionary genetics analysis (MEGA) software version 4.0. Mol Biol Evol 24, 1596-1599.

Thompson, J. D., Higgins, D. G. \& Gibson, T. J. (1994). CLUSTAL W: improving the sensitivity of progressive multiple sequence alignment through sequence weighting, position-specific gap penalties and weight matrix choice. Nucleic Acids Res 22, 4673-4680.

van Ginkel, C. G., Rikken, G. B., Kroon, A. G. M. \& Kengen, S. W. M. (1996). Purification and characterization of chlorite dismutase: a novel oxygen-generating enzyme. Arch Microbiol 166, 321-326.

Voggu, L., Schlag, S., Biswas, R., Rosenstein, R., Rausch, C. \& Gotz, F. (2006). Microevolution of cytochrome $b d$ oxidase in staphylococci 
and its implication in resistance to respiratory toxins released by Pseudomonas. J Bacteriol 188, 8079-8086.

von Wachenfeldt, C., de Vries, S. \& van der Oost, J. (1994). The $\mathrm{Cu}_{\mathrm{A}}$ site of the $\mathrm{Caa}_{3}$-type oxidase of Bacillus subtilis is a mixed-valence binuclear copper centre. FEBS Lett 340, 109-113.
Wu, M. L., Ettwig, K. F., Jetten, M. S. M., Strous, M., Keltjens, J. T. \& van Niftrik, L. (2011). A new intra-aerobic metabolism in the nitritedependent methane oxidizing bacterium 'Candidatus Methylomirabilis oxyfera'. Biochem Soc Trans (in press).

Edited by: J. A. Vorholt 